\title{
CIBERCULTURA
}

\section{O AFASTAMENTO DE DILMA ROUSSEF: AFETOS E DISCURSOS EM DISPUTA NA POLÍTICA}

THE REMOVAL OF DILMA ROUSSEFF: AFFECTIONS AND DISCOURSES IN THE POLITICAL CONTENTION

EL IMPEDIMENTO DE DILMA ROUSSEF: AFECTOS Y DISCURSOS EN DISPUTA EN LA POLITICA

\section{José Luiz Aidar Prado' \\ Vinicius Prates da Fonseca Bueno²}

RESUMO: Este texto examina os sentidos produzidos no Facebook por dois articuladores (Frente Brasil Popular e Vem pra Rua) entre os vários movimentos a favor ou contra o afastamento da presidente Dilma Roussef, em abril de 2016. A análise é feita a partir da teoria do discurso de Laclau e da semiótica tensiva de Zilberberg e Fontanille. As questões de pesquisa são: quais foram os contratos de comunicação e os temas construídos pelos enunciadores situados em lados opostos do espectro político? Quais são as oposições semânticas fundamentais? Que discursos políticos atravessam essas convocações? Quais foram os pontos nodais desses discursos? Como se constrói em cada caso a figura do "povo"? Que afetos um e outro movimento põe em cena? Em termos de uma teoria do acontecimento como se posicionam um e outro enunciador? Em termos tensivos, como entender esses movimentos a partir de uma semiótica da triagem e da mistura? Finalmente, como pensar a construção da democracia a partir dessa polarização?

Palavras-chave: Facebook. Comunicação e política. Discurso. 
ABSTRACT: In this paper we inquire what are the meanings produced by two players (Frente Brasil Popular and Vem pra Rua) at Facebook. They are among the various political movements pro and against the removal of President Dilma Roussef, in April 2016. The analysis is based on Laclau's discursive theory and Zilberbeg and Fontanille's tensive semiotics. The research questions are: which are the communication contracts and themes constructed by this two enunciators, from opposite sides of the political spectrum? Which are the fundamental semantic oppositions? Which political discourses transverse this convocations? Which are the nodal points of those discourses? How do they construct, in each case, the image of 'the people'? What affections do one and another political movements put on scene? What are the positions of these enunciators, through the semiotics of the event therms? Through the tensive semiotics approach, how to understand this political movements with the mechanisms of triage and mixture? Finally, how can we think the construction of democracy from this polarization?

Keywords: Facebook. Communication and politics. Discourse.

RESUMEN: Este texto examina los sentidos producidos en Facebook por dos articuladores (Frente Brasil Popular y Vem pra Rua - Ven a la Calle) entre los varios movimientos a favor y contra el impedimento de la presidente Dilma Roussef, en abril de 2016. El análisis se basa en la teoría del discurso de Laclau y en la semiótica tensiva de Zilberberg y Fontanille. Las cuestiones investigadas son: ¿Cuáles fueron los contratos de comunicación y los temas construidos por los enunciadores situados en lados opuestos del espectro político? ¿Cuáles son las oposiciones semánticas fundamentales? ¿Qué discursos políticos atraviesan estas convocaciones? ¿Cuáles fueron los puntos nodales de estos discursos? ¿Cómo se construye en cada caso la figura del "pueblo"? ¿Qué afectos ponen en escena cada uno de estos dos movimientos opuestos? ¿En términos de una teoría del acontecimiento cómo se posicionan los dos enunciadores enfrentados? En términos tensivos, ¿cómo entender estos movimientos a partir de una semiótica de la selección y de la mezcla? Finalmente, ¿cómo pensar la construcción de la democracia a partir de esta polarización?

Palavras clave: Facebook. Comunicación y política. Discurso.

\section{Introdução}

Neste artigo analisaremos os sentidos produzidos nas páginas do Facebook por dois dos principais articuladores - Frente Brasil Popular, à esquerda e Vem Pra Rua, à direita - da série de movimentos convocados na internet e desembocados nas ruas, durante o afastamento de Dilma Rousseff (Partido dos Trabalhadores - PT), então Presidente da República. Examinaremos o pri- 
meiro passo desse afastamento, em abril de 2016, em que houve (no dia 17) a votação na Câmara dos Deputados. Em abril ela foi substituída interinamente por Michel Temer (Partido do Movimento Democrático Brasileiro - PMDB), que seria confirmado definitivamente no cargo em agosto. A votação do afastamento temporário, no entanto, foi considerada no mundo político como definidora do destino da presidência: se aceito, o afastamento definitivo tenderia a ser protocolar (principalmente se a confirmação da primeira votação no Senado superasse os dois terços dos senadores que seriam necessários para a decisão definitiva em agosto, que caberia à própria câmara alta, o que de fato aconteceu). Exatamente por esse motivo, a votação de abril foi intensamente debatida na imprensa, nas redes sociais e nas ruas.

Buscamos examinar como esses dois movimentos constituíram os seus contratos de comunicação com os seus públicos no Facebook, como se relacionaram com o Outro, como fizeram a ideia de "povo", cada um a seu modo, e como a partir do afastamento produziram diferentes sentidos legíveis a partir dos afetos ali instaurados.

As principais referências desse artigo são a semiótica tensiva de Zilberlberg e Fontanille (2001); a teoria do acontecimento de Badiou (1996); e a teoria do antagonismo de Laclau e Mouffe (2004). Em que pesem as suas diferenças conceituais, eles têm como ponto de diálogo a relativização, senão o abandono, das unidades discretas que eram pensadas em termos opositivos dicotômicos pelo estruturalismo dos anos 1960 e 1970, em direção a uma concepção da linguagem (e do mundo) na qual se sobrepõem as irrupções do acontecimento, dos quais se desdobram os afetos sobre os corpos que sentem e vibram com as percepções que os impactam.

\section{Do quase acontecimento ao acontecimento}

No Brasil houve, no ano de 2013, uma série de protestos massivos de rua que se originaram a partir de uma reivindicação pontual sobre o transporte público (os famosos 20 centavos de acréscimo no preço das passagens de ônibus de São Paulo) e que engrossaram até constituir multidões após uma violenta repressão policial. Depois de alguns dias de manifestação a queixa original havia sido superada ("não é pelos 20 centavos"), e uma série de demandas por ética na política, por condições melhores no atendimento público à saúde e na educação, e contra os gastos considerados excessivos para a promoção da Copa do Mundo de 
futebol, haviam se tornado um patchowrk de vozes e manifestação de interesses que desafiavam a interpretação dos políticos, da imprensa e dos acadêmicos.

Depois das manifestações de 2013 houve polarização entre grupos à esquerda e grupos à direita. Se em julho de 2013 as ruas foram ocupadas por dois principais grupos no campo da esquerda, que Angela Alonso chamou de "autonomistas" e "socialistas" (ALONSO, 2016), depois desse primeiro momento emergiram grupos de direita, principalmente a partir meados de 2015, que apoiaram o impeachment e as pautas neoliberais. Entre os principais estão: à esquerda, Frente Brasil Popular e Povo sem medo, e à direita Vem pra rua e Movimento Brasil Livre. Tais grupos ocuparam as ruas principalmente em 2016, apoiados intensamente nas convocações nas páginas desses movimentos no Facebook.

Nos grupos à direita, com signos de patriotismo verde-amarelo, que começam a atuar em 2015, as principais bandeiras eram o impeachment da então presidente Dilma Rousseff e a destituição do PT do Governo Federal, a anticorrupção representada sobretudo pelo juiz Sérgio Moro e a força-tarefa da operação Lava Jato, com a afirmação de valores tradicionais como o nacionalismo, a família patriarcal a religiosidade e a inviolabilidade da propriedade privada.

Já no campo dos grupos à esquerda uma cisão ficou mais clara desde o princípio entre autonomistas e socialistas. Os primeiros se articulam em torno de pautas políticas horizontais, da multiplicidade de posições identitárias, enquanto os segundos se organizam em torno de um eixo verticalizado em que estão presentes formas mais tradicionais de representação como partidos e sindicatos, associações de classe e movimentos sociais. Os autonomistas tendiam a ser mais abertamente críticos ao governo do PT, enquanto os socialistas eram mais favoráveis a ele.

Os movimentos à esquerda e à direita utilizaram-se das redes sociais online, principalmente o Facebook, a mais usada no mundo, para organizar protestos de rua, comentar criticamente as notícias da grande imprensa, combater os seus adversários políticos, em uma interconexão da produção de sentidos própria da cibercultura contemporânea.

Em linhas gerais se tratarmos as manifestações de junho de 2013 como um quase-acontecimento (OLIVEIRA, 2016), então 2015 e 2016 introduzem uma reação contra um devir que poderia ser acontecimental, no sentido de Badiou, iniciando uma polarização com forte conteúdo afetivo, encarnada em grupos anti e a favor do impeachment. Para dar conta dessa análise, na perspectiva de Badiou (1996) encontraremos a definição do acontecimento como emergência de mudanças no status quo da política; leremos o embate entre uma frente po- 
pular, no sentido de Laclau e Mouffe (1985), tentando construir uma cadeia de equivalências democráticas contra a mobilização hegemônica da classe média alta e das elites política, financeira e industrial; faremos, ainda, o tratamento tensivo da triagem e da mistura da semiótica de Zilberberg e Fontanille (2001).

Realizaremos, portanto, uma análise discursiva e tensiva dos posts do Facebook de dois movimentos, a Frente Brasil Popular (esquerda socialista), e o Vem pra rua (direita liberal) durante o mês de abril de 2016, mês em que se deu o processo de admissibilidade do impeachment na Câmara dos Deputados em Brasília, votado em 17/4.

De acordo com Badiou, o evento ou acontecimento ocorre como uma ruptura radical no mundo, o que ele explica, entre vários exemplos, com o caso de São Paulo, apóstolo cristão, que funda uma nova forma de estar no mundo a partir do evento místico da ressurreição de Cristo (BADIOU, 2009); naquele momento há o rompimento das fidelidades do sujeito desdobradas a partir da Lei hebraica e do logos grego, uma oposição que distribuía os poderes e saberes do Mediterrâneo oriental na antiguidade tardia. O caso do cristianismo a partir de Paulo explica como não é possível, a partir de indícios parciais, remontar o início do acontecimento, o que só pode ser feito a posteriori. Mas, acontecimentos podem ocorrer nos mundos da arte, da ciência, da política e do amor (BADIOU, 1994). Com o acontecimento se rompem as regulações condominiais do status quo dominante e podem aparecer novos mundos, em que novos sujeitos, fiéis ao acontecimento, podem dar continuidade ao processo de verdade iniciado com ele. Não há, portanto, como pensar em uma democratização da política sem a emergência de acontecimentos.

De acordo com Slavoj Žižek:

Numa primeira aproximação, o evento é dessa maneira o efeito que
parece exceder suas causas - e o espaço de um evento é aquele se abre
no intervalo que separa um efeito de suas causas. Já a partir dessa
definição aproximativa, nos encontramos no coração da filosofia,
uma vez que a causalidade é um dos problemas filosóficos básicos:
todas as coisas estão conectadas por nexos causais? (ŽlŽEK, 2014, p.
5, tradução nossa, grifo do autor).

Para Badiou, ao enfrentar esse problema, é preciso fazer uma aposta, já que não há como antecipar ou prever um acontecimento. Este é invenção, e como diz Lazzarato: "Toda invenção é ruptura de normas, de regras, de hábitos que definem o indivíduo e a sociedade. A invenção é um ato que põe o que a reali- 
za fora do tempo histórico e o faz entrar na temporalidade do acontecimento" (LAZZARATO, 2006, p. 69, tradução nossa).

Para Badiou é apenas a ocorrência do acontecimento que propicia o surgimento do sujeito, que só será constituído lançando-se um olhar retroativo sobre o momento que o gerou. Ele entende o sujeito como contingencial e transitório, descrevendo-o da seguinte maneira:

[...] não é uma substância, um ser, uma alma uma 'coisa pensante' como diz Descartes. Ele depende de um processo, começa e acaba [...]. O sujeito não é uma origem. Em particular, não é por haver sujeito que há verdade, mas pelo contrário, porque há verdade há sujeito (BADIOU, 1994, p. 43).

O sujeito surge com o acontecimento, com aqueles que decidem, apostam e se tornam fiéis ao processo de verdade originado com o acontecimento. Esses sujeitos são processuais e encarnados em corpos sensíveis.

\section{Triagem e mistura}

A semiótica tensiva se desloca da narrativa entendida como centro de racionalidade para um campo de presença em que no centro está um corpo que sente e vibra, ou seja, um sujeito perceptivo ${ }^{3}$. As percepções desse sujeito podem ser investigadas a partir de dois eixos: da intensidade e da extensidade, ou seja, das valências afetivas (intensivas, carregadas de mais ou menos tonicidade) e das valências extensivas (ligadas ao espaço e ao tempo, no espalhamento das vibrações nesse campo de presença). Assim, dizem Fontanille e Zilberberg (2001, p. 20): "o corpo próprio é o lugar em que se fazem e se sentem, de uma só vez, as correlações entre valências perceptivas (intensidade e extensidade)". Dizer que as valências têm correlação tensiva significa considerar que elas são graduais e menos ou mais tônicas. As duas valências são reunidas na categoria de valor. Assim:

O caráter atrativo ou repulsivo dos objetos e das junções não depende apenas do conteúdo semântico neles investido: os universos

\footnotetext{
3 A própria movimentação teórica da semiótica nas últimas décadas, antes mais ligada ao percurso gerativo e à narrativa, vai na direção da paixão, cuidando de entender a foria: "Ao lado das oscilações tensivas, reservadas à percepção do ser semiótico, a foria daria conta principalmente dos casos extremos, em que os aspectos sensíveis retirassem do sujeito o controle da situação ou a capacidade de sustentar a própria racionalidade" (TATIT, 2016, p. 19). Ao invés de colocar no centro da análise um enunciador-voz, passa-se a pensa-lo como corpo sensível situado em um campo de presença.
} 
axiológicos devem obedecer previamente a certas condições de composição e homogeneidade, e os valores, por mais desejáveis que sejam, só podem ser procurados e só podem circular sob certas condições de extensidade e intensidade, uma vez que a conjugação das valências intensivas e extensivas modula o fluxo das trocas comunicacionais e, notadamente, o seu andamento temporal (ZILBERBERG; FONTANILLE, 2001, p. 23).

O devir da intensidade distribui ápices e modulações (em ritmos), enquanto o devir da extensidade distribui partes e totalidades no espaço e no tempo, dentro do campo de presença onde o sujeito perceptivo se encontra. Se pensarmos que as apresentações e representações sociais são feitas a partir de elementos reunidos em conjuntos ou classes, então uma semiótica da triagem e da mistura nos ajuda a entender como a tensividade modula as percepções a partir dos valores absolutos ou de universo. De um lado (Figura 1) a triagem tende a separar, a purificar o conjunto, tirando ou acrescentando elementos de modo a torná-lo exclusivo (a partir de valores de absoluto), enquanto de outro a mistura tende a incluir elementos no conjunto (a partir de valores de universo). O exemplo de Zilberberg e Fontanille vem de Tocqueville, que, aristocrático, resolve comparar o antigo regime francês e a democracia americana do século 18 .

Figura 1 - Gráfico tensivo aristocracia $X$ democracia

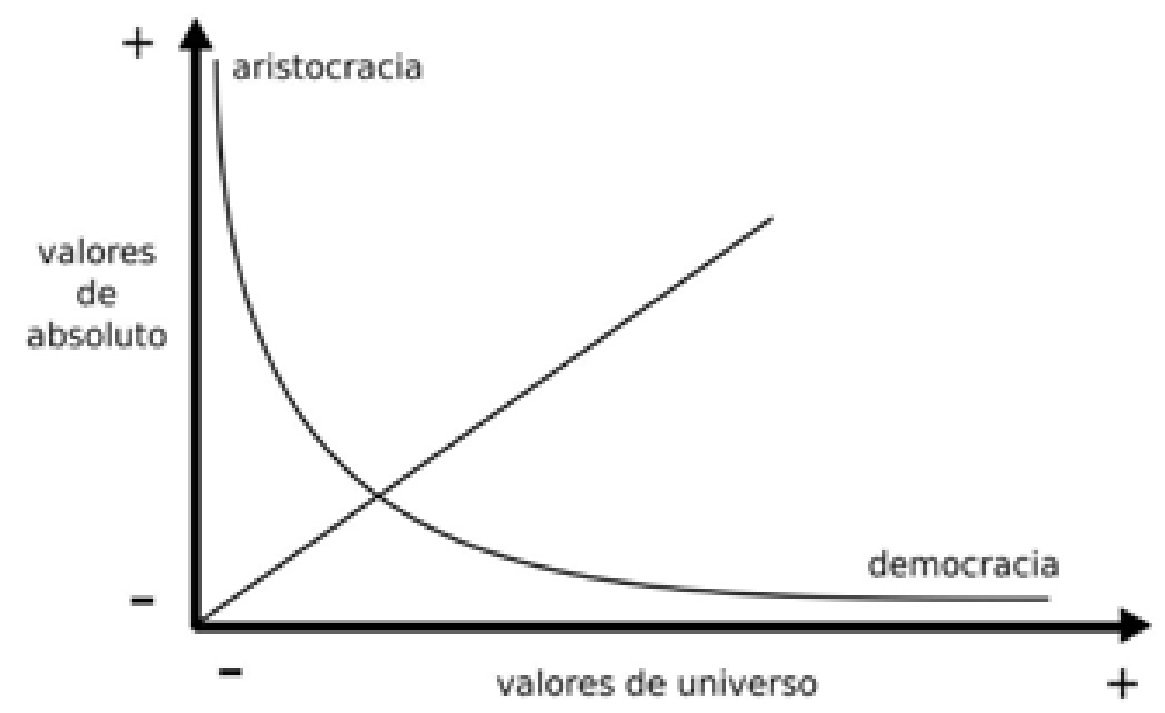

Fonte: Zilberberg e Fontanille (2001, p. 47). 
Para ele o ápice dos valores de absoluto está no sistema aristocrático, enquanto a democracia incide nos valores de universo e ganha em difusão o que perde em termos de intensidade. Nessa visão tocquevilleana, de um lado temos uma intensidade sem extensidade (a aristocracia, o único, o exclusivo), de outro uma extensidade sem intensidade (a democracia, o universal, que deve valer para todos). No primeiro caso o operador dos valores de absoluto é a triagem, o fechamento. No outro caso, o operador dos valores de universo é a mistura, a abertura. Em um caso há concentração, no outro a expansão.

\section{Frente Brasil Popular}

A Frente Brasil Popular foi criada em 10 de agosto de 2015, segundo a sua página de Facebook. Essa página tem o mesmo nome da chapa de três partidos (PT, PSB e PCdoB) que em 1989 disputou, com Luiz Inácio Lula da Silva para a presidência e José Paulo Bisol para a vice, aquelas que foram as primeira eleições diretas para chefe do executivo federal desde a redemocratização. Na ocasião, Lula foi derrotado no segundo turno pelo candidato do pequeno PRN, Fernando Collor de Mello, depois de superar no primeiro turno, por uma pequena margem, Leonel Brizola, do PDT, com quem havia disputado os votos do campo da esquerda. Apesar da derrota, a partir daquela eleição Lula consolidou a sua liderança, ficando também em segundo lugar nas duas eleições seguintes, quando perdeu para Fernando Henrique Cardoso (Partido da Social Democracia Brasileira - PSDB), e vencendo posteriormente em 2002 e 2006. Seu prestígio político ajudou a eleger Dilma Rousseff presidente em 2010 e 2014, cargo que ela exerceu até 2016 quando foi afastada por um processo de impeachment iniciado, como vimos, em abril na Câmara dos Deputados, com o seu afastamento temporário e encerrado em agosto no Senado Federal, com o impedimento definitivo.

O nome da antiga frente partidária, usado 26 anos depois de sua criação no contexto político dos anos 1980, indica uma tentativa do enunciador da página de Facebook de se aproximar dos valores daquela época, cuja organização partidária e sindical (embora já em crise) evocava uma clássica divisão da sociedade em classes econômicas e dava o tom da esquerda mundial.

Na aba "Sobre" (reservada para que os usuários se apresentem), há um texto de 4.359 toques, um chamado "textão" nas gírias das redes sociais online, no qual o enunciador diz que a Frente Brasil Popular ${ }^{4}$ é resultado da união de

\footnotetext{
4 Daqui em diante, utilizaremos a abreviatura "FBP" para Frente Brasil Popular.
} 
[...] militantes de movimentos populares, sindicais, da juventude, negros e negras, mulheres, LGBT, pastorais e partidos políticos, intelectuais, religiosos e artistas reafirmamos a necessidade de derrotar a ofensiva das forças conservadoras e golpistas, propor outra política econômica, para caminhar em direção à transformações estruturais (FRENTE BRASIL POPULAR, [2016])5.

O enunciador segue dizendo que os grupos reunidos na Frente devem ser coligidos em torno de uma "plataforma política mínima", que abarca seis pontos: defesa dos direitos dos trabalhadores e das trabalhadoras; defesa dos direitos sociais do povo brasileiro; defesa da democracia; defesa da soberania nacional; luta por reformas estruturais e populares (neste item o texto cita um documento conjunto aprovado pelos "movimentos populares" em 2014); e defesa dos processos de integração latino-americana.

Em abril de 2016, a FBP teve 75 posts. Em termos temáticos podemos falar em cinco grupos:

a) Nós juntos e diversos: quem está com a FBP? Há vários posts com o título "Juristas, intelectuais, religiosos, artistas e sociedade civil pela democracia", cada um com foto de uma personalidade, entre os quais, Bete Mendes, Leonardo Boff, Fernando Moraes e Teresa Cristina. Vários posts falam da diversidade de movimentos contra o impeachment: "Todas as tribos, cores, raças e etnias estão acampadas em Brasília”. Nas fotos há grande quantidade de jovens, inclusive com foto de uma moça com camiseta do Levante Popular da Juventude. Há posts que falam da abertura de ato com Lula e com lideranças dos movimentos sociais, com indígenas, trabalhadores, estudantes etc. Outro post: "Nenhum outro movimento no Brasil conseguiu reunir tantas bandeiras, tantos movimentos e tanta sede por liberdade". Post do movimento dos estudantes: "Presidente da UNE conclama a manter a resistência". Outros posts falam do movimento das mulheres: "Abraço em Dilma. Como mulheres, sentimo-nos desrespeitadas pelas colocações ofensivas e sexistas de alguns dos parlamentares que votaram ontem a favor da admissibilidade do processo de impeachment". Outro: "Mulheres com Dilma: \#Fica Querida”.

b) Denúncia e convocação à luta: uma série de posts denuncia o golpe contra Dilma e convoca: "Não vai ter golpe - vai ter luta - não ao impeachment e ao ajuste fiscal".

c) Ocupação das cidades: outra série de posts dá notícias sobre o acampamento em Brasília, a partir do qual os manifestantes foram ao Congresso Nacional, ocupando a Esplanada dos Ministérios no dia da votação, para pressionar os deputados. Várias atividades foram anunciadas no acampamento por meio dos posts, com a participação de artistas, músicos, poetas e com exibição de filmes. Um post anuncia que Dilma visitará o acampamento na véspera do impeachment. Outro indica a presença da juventude, dos estudantes: "a juvenália começa as apresentações culturais no palco do acampamento". Há debates também: um deles é sobre a "luta de classes", com João Pedro Stédile; outros debates ocorrem com líderes dos movimentos sociais: União Nacional da Moradia, Movimento de Luta por Moradia, UNE etc. Outros posts se ligam à vida cotidiana no

5 Disponível em: https://www.facebook.com/FrenteBrasilPopular. Acesso em: 20 dez. 2016. 
acampamento: quem chega para estar junto (Diogo, de Minas Gerais, por exemplo); campanha de solidariedade para angariar contribuições; povo esquentando tambores para esperar Dilma e barrar o golpe etc. Há também posts sobre ocupações e manifestações em outras cidades: São Paulo (Av. Paulista e Vale do Anhangabaú; Rio de Janeiro, na praia de Copacabana ("Funk pela democracia - ato furação contra o golpe") e nos Arcos da Lapa; e Marcha da Cultura pela Democracia, em Porto Alegre.

d) Votação na Câmara: posts acompanham a sessão da Câmara e falam da necessidade de continuar a luta: "Nunca vamos esquecer as belas palavras de verdadeiros parlamentares em defesa de nossa tão frágil democracia"; "Hoje é dia de defender a democracia. Nas redes sociais use \#RESPEITE AS URNAS"; "É muito injusto uma mulher honesta ser julgada por um ladrão"; "A divisão de uma parte da sociedade em apoiadores do golpe e defensores da democracia entristece os amigos Douglas Alves e Wendell Segaline"; "Vamos continuar nas ruas e derrotar o golpe". Citações: "A única luta que se perde é aquela que se abandona"(Marighela).

e) Adversários: posts contra políticos golpistas, como Jovair Arantes e contra a Federação das Indústrias do Estado de São Paulo (Fiesp): "por que a Fiesp tem tanto interesse em patrocinar o golpe?"; e posts contra a imprensa. Um deles anuncia que jornalistas dos meios tradicionais foram rechaçados do acampamento, sem violência. Outro afirma: "E se o povo se unir, a Rede Globo vai cair".

Em linhas gerais, podemos resumir os discursos que atravessam esses grupos temáticos em:

f) a) discursos contra aquilo que o movimento caracteriza como "golpe", denunciando o rompimento da ordem democrática por parte do Outro e buscando assim assemelhá-lo às forças políticas que cinco décadas antes haviam deflagrado a ditadura militar a partir de 1964. Com isso, o enunciador estabelece uma linha divisória que euforiza dos valores da "Nova República", como a liberdade e a democracia, em contraposição à velha ordem que se manteve no poder por meios sinistros: pelo uso da repressão, da tortura e da censura. Aqui entram os posts de protesto contra as mídias e a Fiesp, ou seja, contra as elites envolvidas no golpe;

g) b) discurso de ocupação das ruas como movimento de pressão contra a votação, mostrando com imagens o elevado número de pessoas envolvidas em várias cidades e, em particular, no acampamento em Brasília, em que várias atividades foram elaboradas com artistas, políticos, juristas etc, para animar a resistência e debater a ameaça à democracia e aos retrocessos implicados na consequência do golpe;

h) c) ao mesmo tempo, demonstração da diversidade das tribos e movimentos envolvidos na resistência, incluindo feministas, jovens, trabalhadores, sem teto etc., convocando a uma resistência com os afetos de alegria, ligados à música e à força;

i) d) e argumentação de que a convocação para o combate à corrupção era hipócrita, já que a indignação se dirige ao PT e aos grupos de esquerda, mas não incide quando entra em cena o PMDB, o PSDB e os grupos de direita.

Em termos de oposições semânticas fundamentais desses discursos, podemos colocar:

\author{
Legalidade/direitos (democracia) vs. golpe (autoritarismo) \\ Participação popular vs. elitismo
}


Diversidade cultural vs. homogeneidade despolitizada

Os pontos nodais desses discursos são democracia popular e proteção de direitos fundamentais, conjunção de diferenças, política como luta participativa, e justiça contra hipocrisia. Os pontos nodais são aqueles que, como dizem Howarth e Stavrakakis (2000), anulam as diferenças e articulam uma rede de equivalências simbólicas que sustenta um discurso. Os discursos que se embatem em antagonismos em determinado campo disputam a estabilização desses pontos:

As práticas hegemônicas pressupõem um campo social atravessado por antagonismos que podem ser articulados por projetos políticos opostos. O principal objetivo dos projetos hegemônicos é construir e estabilizar os pontos nodais que formam a base de ordens sociais concretas ao articular tantos elementos disponíveis - significantes flutuantes - quanto for possível (HOWARTH; STAVRAKAKIS, 2000, p. 15, tradução nossa).

Em termos de circuitos dos afetos circulam nesses discursos os afetos ligados à comunidade e à força intensiva para a luta contra as elites (os parlamentares corruptos, as mídias, a Fiesp), a alegria de estar juntos (diversidade; união na diferença) contra o golpe; e a animação de fazer multidão como forma de impor desejo por justiça e por verdade (contra o mascaramento do golpe, contra o cinismo das elites ao propor impeachment, mesmo não havendo provas contra Dilma). A alegria e a intensidade convocam à formação de uma multidão resistente, por um lado e, por outro, há a oposição (afetos mais ligados ao enfrentamento) contra uma direita golpista, antidemocrática e defensora de interesses de classe.

\section{Vem pra Rua}

O Vem Pra Rua (VPR), tem uma página de Facebook criada em 16 outubro de 2014, curiosamente entre o primeiro e o segundo turnos das eleições, disputados respectivamente no dia 5 e no dia 26 daquele mês. $O$ segundo turno trouxe o confronto entre Dilma Rousseff (PT) e Aécio Neves (PSDB). O movimento se diz apartidário, e convoca os seus enunciatários a participarem de movimentos de massa nas ruas, mesmo no auge do período eleitoral - em um apelo à participação política para além do ato de votar.

No lugar destinado à sua própria apresentação na página da mídia social, o enunciador posta um texto de 2.367 toques, divididos em seis parágrafos, nos quais se declara contra o Governo da época, mas também se diz contra os "po- 
líticos corruptos", e alega que a forma de combatê-los é por meio de "grandes manifestações cívicas". No primeiro, no terceiro e no quinto parágrafos, o texto insiste que seus protestos, em oposição pressuposta à esquerda, são ordeiros e pacíficos, e que os membros do movimento abominam a violência, agem dentro da lei e do Estado de Direito.

Há também nesse texto de apresentação uma série de referências que disforizam o poder público, indicado ou pressuposto como corrupto, antiético, incompetente, e que euforizam a eficiência, o empreendedorismo e a livre iniciativa:

É onde a liberdade econômica é estimulada e o Estado não é maior que o necessário, a fim de que o empreendedorismo e a livre iniciativa gerem riquezas e oportunidades para todos. Acreditamos na força do povo brasileiro, na sua capacidade inventiva, na sua generosidade e no seu trabalho - e num Estado que garanta minimamente segurança, educação básica, saneamento básico e saúde pública para todos. Queremos menos impostos e mais Brasil. Queremos uma sociedade que ofereça igualdade de oportunidade a todos, sem distinção. Queremos mais concorrência e menos clientelismo (VEM PRA RUA, [2016]). ${ }^{6}$

No penúltimo parágrafo o movimento busca se distanciar de outros grupos de direita que se manifestaram contra o próprio sistema democrático (que pedem intervenção dos militares):

Somos a favor da democracia, da ética na política e de um Estado eficiente e desinchado. Somos contra qualquer tipo de violência e condenamos qualquer tipo de extremismo (separatismo, intervenção militar, golpe de Estado) e não compactuamos com governos autoritários (VEM PRA RUA, [2016])7.

Em que pesem as invectivas neoliberais e as declaradas convicções democráticas, o final do manifesto (que é lido em uma página encabeçada por uma fotografia de uma multidão levando uma imensa bandeira bicolor verde e amarela na Avenida Paulista) é encerrado com uma sentença de tom nacionalista totalitário:

6 Disponível em: https://www.facebook.com/VempraRuaBrasil.org. Acesso em: 15 dez. 2016.

7 Disponível em: https://www.facebook.com/VempraRuaBrasil.org. Acesso em: 15 dez. 2016. 
E assim, vamos clamar juntos por um Brasil ético, justo, próspero e com valores sólidos. E, acima de tudo, por um Brasil unido! O NOSSO PARTIDO É O BRASIL.

VEM PRA RUA! (VEM PRA RUA, [2016])8

Em abril de 2016, o Vem Pra Rua teve 63 posts. Em termos temáticos podemos falar em seis grupos:

j) Nós juntos em uníssono: quem está com o VPR. Hélio Bicudo, Victor Fasano, Marcio Garcia.

k) Adversários e denúncia contra as mentiras e ações de Dilma e do PT. Há uma série de posts no dia 1 de abril, dia da mentira, e posts afirmando "Chega Lula, Chega PT, seu tempo acabou", mostrando que Dilma estava contra o povo. Outros posts explicam as pedaladas do governo sob Dilma. Há mais de um post contra o Advogado Geral da União, José Eduardo Cardoso, acusado de trabalhar somente para Dilma. O enunciador pergunta: Cardoso cuida de Dilma, e quem cuida da União?

I) Ocupação das cidades: vários posts de abril convocam para ocupação das ruas, para pressionar os parlamentares a votarem pela admissão do impeachment; a principal é a convocação para 17 de abril, dia da votação. Mas houve também outras multidões de rua, como em 3 de abril. Outros posts falam de movimentos em outras cidades, como em Aracaju, Roraima, Uberlândia, e de uma carreata em Natal. Nessa, é mostrado o prédio de um deputado indeciso.

m) Votação na Câmara: posts acompanham a votação da Câmara. Líderes do VPR vão a Brasília durante o mês e durante a votação. Vários vídeos apresentam a situação para os internautas, sempre tentando fazer pressão aos deputados indecisos. Em um dos posts é mostrada a distribuição do Livro do impeachment aos deputados, com a justificação do impeachment.

n) Mapa contra indecisos: o VPR elabora um Mapa para acompanhar quais deputados votariam a favor, contra e os indecisos. Convocam os internautas a pressionar os indecisos. Isso ocorre durante todo o mês de abril, em muitos posts.

o) Outros: um post afirma "sem impeachment, sem investimento", atribuindo a culpa da crise a Dilma; outro pergunta: "que golpe é esse?"; outro: "nem os petistas acreditam - Debandada de prefeitos que mudaram de legenda";

As oposições semânticas são:

Progressistas patriotas vs. corruptos mentirosos e traidores.

Povo vs. petistas

Em termos políticos, não há muita discussão de qual Brasil é preciso construir após o impeachment. Para o VPR, basta fazer o impeachment e retirar do poder o PT para o País voltar a crescer. Fala-se em democracia, mas não se explicita que democracia é essa, o que ela deve envolver. O slogan do VPR é "democracia sempre. Justiça já". Nesse sentido os discursos dominantes nos posts do VPR

8 Disponível em: https://www.facebook.com/VempraRuaBrasil.org. Acesso em: 15 dez. 2016. 
são os da luta contra a corrupção; da luta contra o PT. O estar junto aqui é para derrubar, não para construir. A construção fica nas mãos do mercado e de um governo enxuto, idealizado como não corrupto, o que não leva em conta a força do pemedebismo há décadas._Aqui o povo é o conjunto da população que está contra o PT, mas se trata de um uso alargado da palavra "povo". Em Laclau (2013) só surge povo quando há uma rede equivalencial que minimiza as diferenças, estabelecendo pontes e diálogos entre elas, de modo a constituir uma frente contra os adversários dominantes, que detêm a hegemonia na política.

O ponto nodal dos discursos do VPR está mais do lado da justiça, não entendida como justiça social, de distribuição e reconhecimento (FRASER; HONNETH, 2006), mas contra a corrupção, que fica centrada no PT, quando se sabia que atingia a todos os partidos. A democracia aparece sentada em berço esplêndido, como se não fosse necessário discuti-la e construí-la. O que incomoda o VPR é o poder nas mãos da esquerda, mas se ignora que para governar é preciso fazer composições com o pemedebismo, aqui entendido como um partido voltado para "marginalizar a grande massa da população" a partir de uma "cultura política de subordinação e de mando, antidemocrática, por dispositivos sociais, políticos e econômicos que reprimem e marginalizam todo movimento de democratização e de auto-organização" (NOBRE, 2013, p. 186). O pemedebismo não parece incomodar o VPR, exceto no que se refere a algumas figuras pontuais como Renan Calheiros, ligado ao tema da corrupção, jamais no tema da construção da própria democracia. "Democracia" e "povo" para o movimento são significantes retóricos, mais ligados à liberdade do que à justiça social, que deveria envolver a massa da população e não somente a elite e as classes médias de maior poder aquisitivo e de influência. Fica implícita aí uma visão liberal da política. Sempre que se fala do impeachment nunca se explicita as razões, atribuindo-se a análise aos juristas, que escrevem no Livro do impeachment, que foi distribuído aos deputados em Brasília. em um dos posts se diz "Chega Lula, chega Dilma, chega PT. O povo não aceita mais esse tipo de política rasteira que Lula promove. Entre no mapa do impeachment e faça pressão nos indecisos". Ora, que "política rasteira" é essa? $\mathrm{Na}$ verdade é a política do pemedebismo, a que o lulismo aderiu para governar, mas o pemedebismo jamais é posto em questão pelo VPR. Isso configura uma espécie de democracia despolitizada, não argumentada. 


\section{Em torno do significante "povo"}

Segundo Laclau (2013) para haver povo é preciso que haja uma lógica das equivalências que unifique as diferenças em torno de certos pontos nodais. No caso da FBP a promoção da equivalência se dá a partir da união em torno da luta contra o impeachment, que implica em combater as elites de direita que querem desmontar o que ainda restou de direitos sociais conquistados nas últimas décadas em termos de habitação, educação, direitos das minorias, saúde etc. Temos assim precondições para o surgimento da articulação do populismo (termo que para Laclau não deve ser tomado com a má vontade que normalmente o acompanha nas ciências políticas), ou seja, para a construção de um povo para além da evocação hipócrita de "povo". Essa articulação se dá em duas etapas: a formação de uma fronteira interna antagônica separando o "povo" do poder; e uma articulação equivalencial de demandas que faz possível o surgimento do "povo" (a partir disso a construção de uma cadeia equivalencial que é mais do que a soma de suas partes). O populismo, a construção de um povo, dessa forma, não é a identidade ideológica de um grupo já estabelecido: ele é uma das formas de constituir a própria unidade do grupo. Laclau diz, sobre as teorias políticas clássicas:

A principal dificuldade com as teorias clássicas da representação política é que a maioria delas concebeu a vontade do povo como algo constituído antes da representação. Isto é o que corre com o modelo agregativo da democracia (Schumpeter, Downs) que reduz o povo a uma pluralidade de interesses e valores, e com o modelo deliberativo (Rawls, Habermas), que encontrou tanto na justice as fairness ${ }^{9}$, como nos procedimentos dialógicos, as bases de um consenso racional que eliminaria toda a opacidade nos processos de representação. Uma vez que chegamos a esse ponto, a única pergunta relevante é como respeitar a vontade dos representados, tomando como fato que esta vontade exite em primeiro lugar (LACLAU, 2005, p. 206, grifo do autor, tradução nossa).

Em Laclau essa lógica se inverte: só há povo quando o povo vai se reconhecendo como povo, ao construir uma lógica equivalencial entre as diferenças que constituem os grupos dentro desse povo em formação e contra a lógica dos

9 Em inglês na edição espanhola. 
dominantes. Não é a única, já que existem outras lógicas que operam no social e que fazem possível identidades diferentes da populista. Como diz o autor:

[...] a frustração de uma série de demandas sociais faz possível a passagem de demandas democráticas isoladas a demandas populares equivalenciais. [...] Sem essa ruptura inicial de algo em torno da ordem social - por menor que que essa ruptura tenha sido inicialmente - não há possibilidade de antagonismo, de fronteira ou, em última instância de "povo". Contudo, esta experiência inicial não é só uma experiência de falta. A falta, como vimos está vinculada a uma demanda não satisfeita. Mas isso implica introduzi no quadro a instância que não satisfez a demanda. Uma demanda sempre é dirigida a alguém. É por isso que nos deparamos desde o início com uma divisão dicotômica entre demandas sociais insatisfeitas, por um lado, e um poder insensível a elas, por outro. Aqui começamos a entender por que a plebs percebe a si mesma como o populus, a parte como o todo [...] (LACLAU, 2005, p. 112-113, tradução nossa).

No caso da FBP vemos a nítida tentativa de construção de um povo, embora a verticalização do movimento, mais ligado aos sindicatos e movimentos tradicionais da esquerda torne difícil a efetivação de uma lógica equivalencial que ultrapasse a lógica das diferenças entre diversos grupos contra-hegemônicos (tanto tradicionais quanto autonomistas) constituintes da Frente. Essa formação da equivalência seria mais fácil talvez no caso dos movimentos autonomistas, embora a organização espontânea e horizontal desses movimentos muitas vezes os torne efêmeros, como se tem visto nos últimos anos em todo o mundo.

A modulação dos discursos encampados pela FBP visa uma acontecimentalização do encontro na multidão, em torno da construção e manutenção de um mundo de direitos e de melhorias para os grupos mais pobres e menos empoderados da população, para a plebs, que será constituída como populus: aqueles que são uma parcela distinguida pela falta (de saúde, moradia, educação etc.), e que dirigirão as suas demandas a uma elite, passam a ser o todo do povo.

\section{Afeto e tensividade}

A partir da semiótica tensiva podemos agora examinar dois pontos relevantes: 1) a moralização; e 2) os afetos, a foria para levar a luta adiante. A moralização é abordada por Greimas e Fontanille na Semiótica das Paixões (1993). Moralizando- 
se a paixão, avalia-se não apenas uma maneira de fazer ou de ser, mas certa maneira de ser apaixonado. Aqui a maneira da esquerda de estar junto na multidão é muito diferente daquela da direita, que se reúne convocada mas não acampa, não participa senão no "panelaço" e em situações pontuais como em frente à Fiesp, na avenida Paulista, onde essa distribuiu até mesmo bifes de filé mignon; depois volta à vida individualizada/individualizante.

$\mathrm{O}$ afeto principal do lado da FBP é aquele ligado à alegria de estar junto, defendendo uma democracia ameaçada pelo autoritarismo e pelo desmonte neoliberal das conquistas democráticas ligadas aos direitos. A estratégia para os grupos da esquerda (FBP) na direção do empoderamento na luta firme e forte é a alegria do encontro na direção do enfrentamento dos poderes elitizados e neoliberais. A música e a arte entram nessa composição de um corpo na multidão. "Afinal, o que define um acontecimento senão o seu ingresso veloz num campo de presença, reduzindo ao mínimo tanto a duração quanto o espaço subjetivo de um sujeito implicado?" (TATIT, 2016, p. 24).

No caso do VPR, a alegria é mais contida, mais ligada à ordem, ao funcionamento ordeiro de instituições que não devem ser pressionadas pelo Estado hipertrofiado, e menos ligada à mudança para ampliação de direitos e conquistas efetivamente populares; aqui os afetos são colocados na destituição da presidente, no fazer ruir o PT, na retomada do poder, embora isso fique mais implícito do que realmente tematizado. É, portanto, um movimento de reação, não um movimento acontecimental que poderia fomentar a construção da democracia. É a alegria do sujeito que quer preservar a sua condição de classe média ascendente ou rica. O pemedebismo nesse discurso é invisível, exceto quando o VPR fala contra Renan e algumas poucas figuras, acusadas de corrupção.

Como vimos ao falar da visão tocquevilleana, com a polarização entre valores absolutos (aristocracia, exclusivo e único) e valores universais (democracia, universal), é justamente o que ocorre com os movimentos de direita e de esquerda. No caso do Vem pra rua e do Movimento Brasil Livre (MBL) há a concentração, a busca do mérito, do exclusivo, e a retirada dos elementos que não merecem ter os direitos atendidos por parte do Estado (ou estes deveriam ser minimizados). O discurso neoliberal adotado por esses movimentos aponta como "vagabundos" aqueles que defendem os direitos de habitação, saúde e educação dos pobres e os direitos das minorias. No caso dos movimentos de esquerda, como a FBP, há a defesa de um discurso democrático, de acesso de direitos aos sem parcela, os sem voz, construindo um movimento inclusivo, de expansão. 


\section{Considerações finais: os sentidos da democracia}

Em um caso e em outro a palavra "democracia" assume, como vimos, sentidos muito diversos. "Para o discurso que visa os valores de absoluto, o máximo de intensidade está associado à unicidade, ou seja, a uma grandeza definida por sua tonicidade e sua exclusividade" (ZILBERBERG; FONTANILLE, 2001, p. 48). Aqui a universalidade é negativa e a abertura se dá ao custo "de uma queda de intensidade" (ZILBERBERG; FONTANILLE, 2001, p. 49). No outro discurso, o dos valores de universo, os valores importam em função de sua extensão (a diversidade dos movimentos, a ampliação dos direitos na FBP), de sua possibilidade de universalização.

Os polos não são isolados, havendo movimento de um lado a outro, na medida em que ocorre pressão social pela circulação dos valores. Em um microuniverso dirigido pelos valores de absoluto, a participação é obtida por melhoração (Figura 2). Em um microuniverso dirigido por valores de universo, a exclusão é obtida por pejoração (elementos maus são retirados). Nesse sentido a aliança é impura, ligada a uma universalização dos valores, se opondo à pureza dos valores exclusivos. A ida da pureza dos valores exclusivos para valores universais é dita melhoração; a ida do princípio de participação aos valores exclusivos (pureza) é dita pejoração.

Figura 2 - Tráfego entre valores absolutos e universais
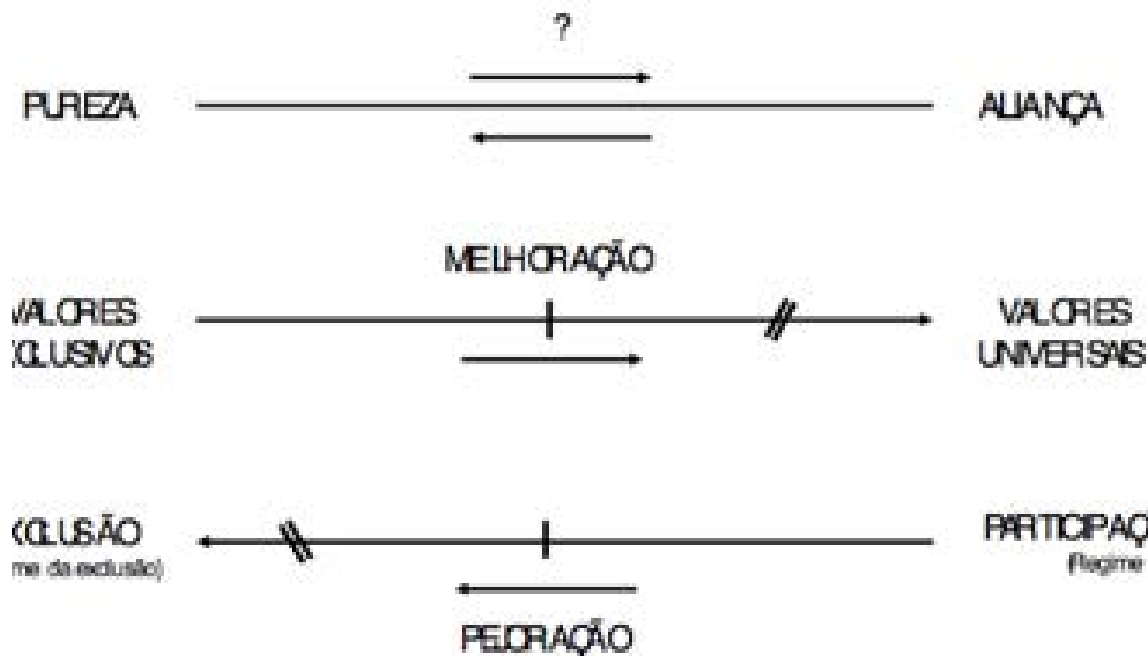

PARTCPAC̆OO (princ Plogme da mitural 
Na construção de um país democrático é preciso que os confrontos antagonistas não levem a uma polarização imobilista (aliás nosso imobilismo vem sendo construído historicamente pelo pemedebismo), mas caminhe, através da melhoração, para valores mais universais, sob a ação de uma semiótica política da mistura; aí entra a importância da mestiçagem.

Para Zilberberg a mestiçagem é uma prática semiótica inaugural e pode ser abordada como uma variedade da mistura. A mestiçagem tem valência intensiva fraca e alta valência extensiva. Ela está do lado dos valores universais e da aliança. O que isso significa? Zilberberg explica:

\footnotetext{
O quantum de afeto disponível seria constante e divisível, de tal maneira que, se a operação de triagem se tornou impraticável, o quantum de afeto atribuído a uma única grandeza é máximo ou, por outras palavras, sublime. Em contrapartida, se se proceder a uma operação de mistura e depois, por recursividade, a uma série de operações de mistura, haverá ao mesmo tempo uma difusão extensiva e uma diluição intensiva, com que cada grandeza implicada no processo receberá uma quantidade menor; a repetição da operação age como um divisor cujo aumento provoca a diminuição, na mesma proporção, do quociente (ZILBERBERG, 2004, p. 75).
}

Isso nos leva, de acordo com ele, a uma semiótica do afeto, um "tratamento analítico do afeto", em que uma dialética da difusão e da diluição seria independente dos conteúdos semânticos. Considerando a aproximação entre duas grandezas ou o seu afastamento, por um lado e, por outro, a aderência ou a inerência, pode haver quatro casos possíveis (cf. figura 3): separação, contiguidade, mescla, fusão. No caso da separação, a valência da triagem é plena, a da mistura é nula; na fusão ocorre a inversão desse caso, com triagem nula e mistura plena. A contiguidade e a mescla administram valências médias: na primeira, a triagem domina a mistura, na segunda a triagem é a dominada.

Além dessa variação de tonalidade, para Zilberberg a aspectualização do devir (ou seja, o devir visto em processo, no tempo) é sempre condicionada pelo andamento, ou seja, o processo de mistura pode ser mais lento ou mais acelerado: "neste, a síncope da contiguidade e da mescla transformam o advir em sobrevir, já que o processo passa sem transição, e principalmente sem retardamento para o observador, da separação à fusão" (ZILBERBERG, 2004, p. 77). 
Figura 3 - Gráfico tensivo da triagem e da mistura

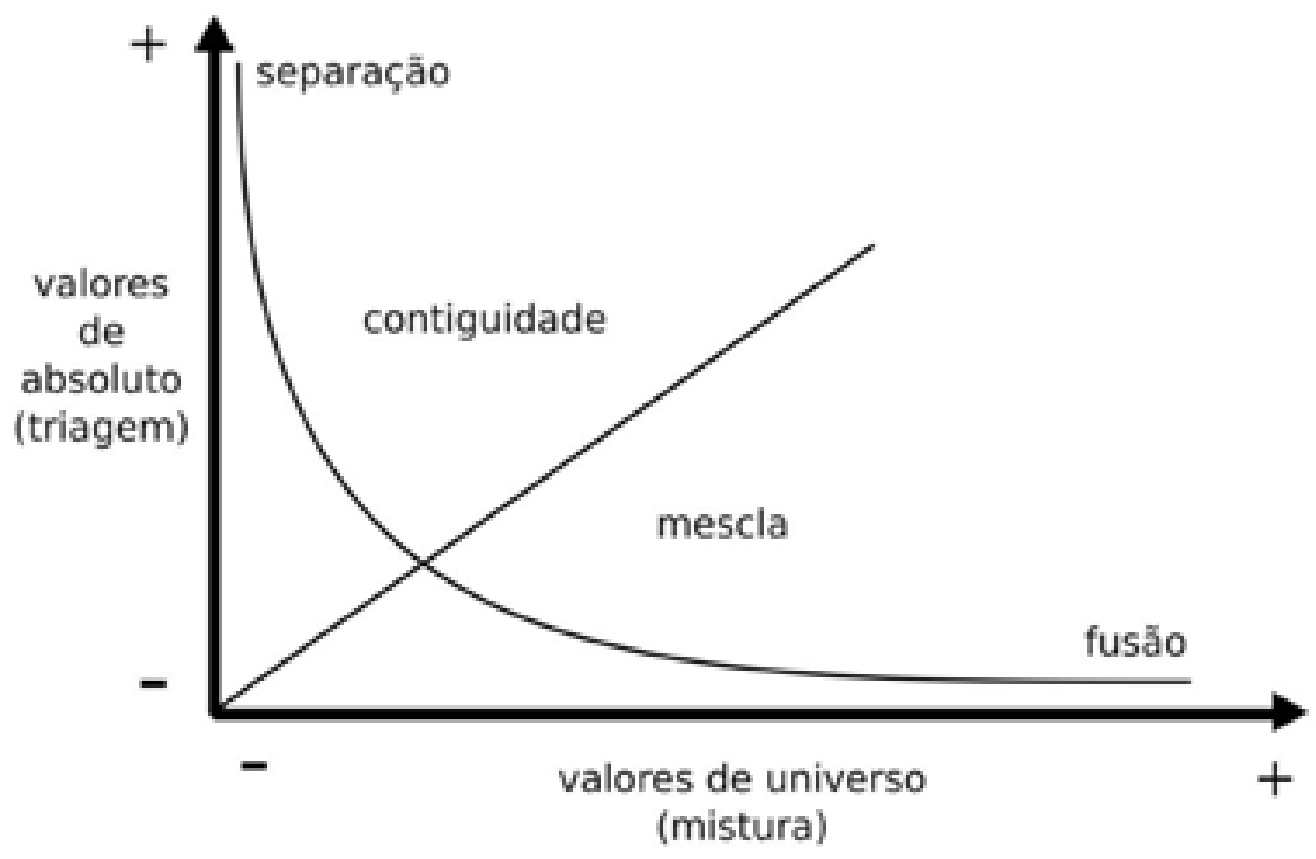

Fonte: Zilberberg (2004, p. 77).

A contenda simbólica entre FBP e MBL nos conduz a pensar o confronto antagonista sobre os sentidos do acontecimento (ou, como dissemos antes, do quase acontecimento) a partir da semiótica da triagem e da mistura, na direção da mestiçagem. Enquanto os movimentos populares buscam a diversidade e os valores de universo, os movimentos à direita buscam justamente o fechamento do conjunto dos merecedores, dos Eus S/A, caracterizados pelo que Safatle (2012) chama de "figura atual do humano", a imagem capitalizada, alfa, que tem visibilidade e crédito simbólico. A questão é: como ultrapassar a polarização cheia de ódio entre esquerda e direita em direção a mundos mais mestiços?

\section{Referências}

ALONSO, Angela. A política das ruas. Folha de S. Paulo, llustríssima, 25/09/016. Disponível em: http://www1.folha.uol.com.br/colunas/angela-alonso/2016/o9/ 1816167-a-politica-das-ruas.shtml. Acesso em: 10 nov. 2016. https://doi.org/10.25091/ s01013300201700040006

BADIOU, Alain. Para uma nova teoria do sujeito: conferências brasileiras. Rio de Janeiro: Relume-Dumará, 1994. 
BADIOU, Alain. O ser e o evento. Rio de Janeiro: Zahar/UFRJ, 1996.

BADIOU, Alain. São Paulo: a fundação do universalismo. São Paulo: Boitempo, 2009.

FRASER, Nancy; HONNETH, Axel. Redistribución o reconocimiento? Madri: Paideia/ Morata, 2006.

FRENTE BRASIL POPULAR. Sobre. Página de Facebook. Disponível em: <https://www. facebook.com/FrenteBrasilPopular>. Acessado em: 20 dez. 2016.

GREIMAS, Algirdas Julien; FONTANILLE, Jacques. Semiótica das paixões: dos estados de coisas aos estados de alma. São Paulo: Ática, 1993.

HOWARTH, David; STAVRAKAKIS, Yannis. Introducing discourse theory and political analysis. In: HOWARTH, David; NORVAL, Aletta; STAVRAKAKIS, Yannis (Org.). Discourse theory and Political Analysis: Identities, hegemonies and social change. Manchester/New York: Manchester University, 2000. https://doi.org/10.1177/03058298000290030918

LACLAU, Ernesto. La razón populista. Buenos Aires: Fonde de Cultura Económica, 2005.

LACLAU, Ernesto; MOUFFE, Chantal. Hegemonía y estrategia socialista: hacia una radicalización de la democracia. Buenos Aires: Fonde de Cultura Ecomómica, 2004.

LAZZARATO, Maurizio. Políticas del Acontecimiento. Buenos Aires: Tinta limón, 2006.

NOBRE, Marcos. Imobilismo em movimento: da abertura democrática ao governo Dilma. São Paulo: Cia das Letras, 2013.

OLIVEIRA, Luciana de. Visões de um quase acontecimento: desenvolvimento, sustentabilidade e as disputas de sentido no debate midiático sobre Belo Monte. In: Antropologia da comunicação de massa. Campina Grande: Universidade Estadual da Paraiba, 2016. https://doi.org/10.7476/9788578793326.0011

SAFATLE, Vladimir. Grande hotel abismo: por uma reconstrução da teoria do reconhecimento. São Paulo, Martins Fontes, 2012.

TATIT, Luiz. Claude Zilberberg e a prosodização da semiótica. In: MENDES, Conrado Moreira; LARA, Glaucia Muniz Proença (org.). Em torno do acontecimento: uma homenagem a Claude Zilberberg. Curitiba: Appris Editora, 2016. https://doi.org/10.21709/ casa.v7i2.2227

VEM PRA RUA. Sobre. Página de Facebook. Disponível em: https://www.facebook. com/VempraRuaBrasil.org. Acessado em: 15 dez. 2016.

ZILBERBERG, Claude. As condições semióticas da mestiçagem. In: CAÑIZAL, Eduardo Peñuela; CAETANO, Kati Eliana (org.). Olhar à deriva. Mídia, significação e cultura. São Paulo: Annablume, 2004. 
ZILBERBERG, Claude; FONTANILLE, Jacques. Tensão e significação. São Paulo: Humanitas, 2001.

ŽIŽEK, Slavoj. Event: philosophical journey through a concept. Londres/Nova York: 8 Blackstock Mill e Melville House, 2014.

\section{Dados dos autores}

José Luiz Aidar Prado - aidarprado@gmail.com

Professor doutor do Programa de Estudos Pós-graduados em Comunicação e Semiótica da PUC-SP; editor da revista Galáxia; autor de Habermas com Lacan e de Convocações biopolíticas dos dispositivos comunicacionais e coordenador e organizador da hipermídia Regime de visibilidade em revistas. Coautor de Sintoma e fantasia no capitalismo comunicacional.

Endereço: Programa de Estudos Pós-graduados em Comunicação e Semiótica, Pontifícia Universidade Católica de São Paulo - R. Monte Alegre, 984 - Perdizes - São Paulo (SP), Brasil

Vinicius Prates da Fonseca Bueno - viniciusprates.vp@gmail.com

Doutor em Comunicação e Semiótica pela PUC-SP e coautor de Sintoma e Fantasia no Capitalismo Comunicacional.

Endereço: Centro de Comunicação e Letras, Universidade Presbiteriana Mackenzie - Rua Piauí, 143 - Higienópolis - São Paulo (SP), Brasil 